\section{NOTES FOR THE R.M.O. OF AN INFANTRY UNIT}

By C. P. Blacker. Oxford War Manuals, London. I943. Price 5 s.

The author of this book has had the uncommon experience of serving as a combatant officer in a battalion in I9I4, and returning to the same battalion as an R.M.O. in I939. He was thus a medical officer uniquely qualified for his task; and he has written precisely the book which many of us would have given anything to possess at the beginning of the war. It is neatly written, informal and concise: discusses the R.M.O.'s responsibilities under 16 short separate heads, each containing the sort of information which an officer is not likely to pick up on an official course, but which nevertheless is the essence of wisdom for him when he comes to handle his men. It is the distillation of 3 years regimental experience. The average R.M.O. evolves for himself, in time, a drill for his various duties; how much time and experimentation it would save if this small book were made available at the beginning of his regimental life. I have no doubt that nowadays training courses for R.A.M.C. officers are intelligently organised, so that much of what is here is actually taught as a routine: at the beginning of the war this was not so.

The author emphasises, in his preface, what is too often forgotten, that however good the medical organisation of a unit is, there is always room for improvement: the R.M.O. should exercise an unceasing vigilance to see that this improvement is maintained. A distinction is implied here on which I think more stress should be laid: that is, the distinction between officers in a Field Ambulance and regimental medical officers of a unit. There is a certain overlap between their duties: and of course a close liaison must be maintained, but I think many officers, having been posted to a unit and got to know the men, would prefer to remain there, and forego transfer to a Field Ambulance and subsequent promotion. The R.M.O. is an integral part of his regiment or battalion: his C.O. is generally reluctant to change him, and it is arguable that the interests of the service would be best served if these two classes of officers were not interchangeable. Time spent as R.M.O. to a unit is never wasted: at the end of his service, he may know less about Frohlichs Syndrome, but he will know a great deal more about his fellow men and the maintenance of health, which is the foundation of the medicine of the future.

CORRECTION

\section{PSYCHOPATHOLOGY}

By J. ERnest Nicole. 3rd edition. Baillière, Tindall \& Cox, I.ondon. I943.

The price of this book is $I_{5}$ s., not $5 \mathrm{~s}$. as incorrectly stated in the review appearing in the December I 943 issue.

\section{FOR}

THE MOST

EFFECTIVE

PRACTICE OF

ACTINOTHERAPY

\section{$\star$}

We have recently published a new Medical Prospectus under the title "Equipment for Actinotherapy". This title errs, if at all, on the side of modesty for the booklet in fact contains a very full description and many fine and detailed illustrations of a very complete range of lamps for both ultra-violet and infra-red irradiation. This range comprises models for use in service and civil hospitals, for private practice and for prescription.

You will, we think, find the booklet valuable for reference quite apart from its purely 'catalogue aspect' and we believe you will wish to keep a copy on your files.

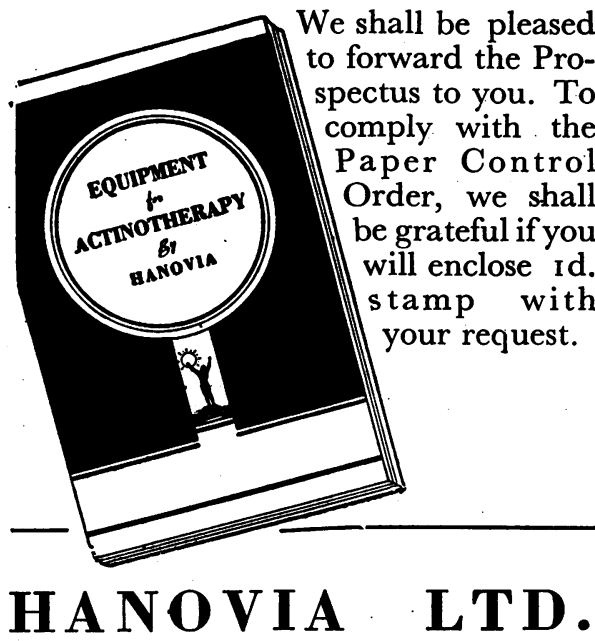

Specialists in Actinotherapy Equipment

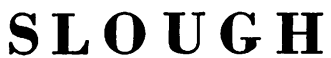

London Showrooms; 3 Victoria Street, S.W.r

MI2I/20 